\section{Efficacy and safety data based on historical or pre-existing conditions at baseline for patients with active rheumatoid arthritis who were treated with baricitinib}

Patients with rheumatoid arthritis (RA) have a high prevalence of comorbidities. ${ }^{1}$ This post-hoc analysis investigated the effect of select comorbidities (depression, osteoporosis, hepatic, cardiovascular or pulmonary disorders) on the efficacy and safety of baricitinib $4 \mathrm{mg}$ once daily in patients with moderate-to-severe active RA and an inadequate response to conventional synthetic disease-modifying antirheumatic drugs (csDMARDs).

Data from the placebo-controlled periods of five baricitinib studies $^{2-6}$ were pooled for baricitinib $4 \mathrm{mg}$; data for baricitinib $2 \mathrm{mg}$ were not analysed due to low $(\mathrm{n}=302)$ patient numbers. Additional data for all baricitinib-treated patients with a median exposure of 2 years were derived from an ongoing open-label, long-term extension (LTE) study that included patients from phase II and III studies (RA-BEYOND; NCT01885078). ${ }^{7}$ Efficacy outcomes were evaluated at week 12 (vs placebo). Interaction of comorbidity-by-treatment was analysed using logistic regression or analysis of covariance. Safety observations up to week 16 (vs placebo) and during the LTE were summarised by the Medical Dictionary for Regulatory Activities preferred term.

Data from 1684 patients (803, baricitinib $4 \mathrm{mg}$; 881, placebo) from the placebo-controlled periods were analysed. The mean (SD) age was 52.7 (12.1) years, with only 38 (2.3\%) patients aged $\geq 75$ years; most patients $(1506,89.4 \%)$ were receiving background methotrexate, alone or in combination with another csDMARD. The numbers of patients receiving placebo and baricitinib $4 \mathrm{mg}$ combined (with or without each comorbidity, respectively) were 133/1551 for depression, 247/1437 for osteoporosis, 424/1260 for hepatic disorders, 731/953 for cardiovascular disorders, and 166/1518 for pulmonary disorders. Demographic and clinical characteristics within each comorbidity subgroup were similar between patients randomised to baricitinib or placebo.

Higher proportions of patients achieved all clinical endpoints with baricitinib $4 \mathrm{mg}$ than with placebo at week 12 across subgroups (table 1). Response rates in patients with or without each comorbidity who received baricitinib were generally close to overall response rates, with the exception of depression, where numerically lower response rates were observed in patients with versus without depression and overall (table 1). Responses to baricitinib versus placebo were similar between patients with or without comorbidity within each comorbidity subgroup, even for those with/without depression $(p>0.1)$.

The safety analysis set from the placebo-controlled periods included 1683 patients (802, baricitinib; 881, placebo) with 235.2 and 246.9 patient-years of exposure (PYE) to baricitinib $4 \mathrm{mg}$ or placebo, respectively. Similar proportions of patients experienced $\geq 1$ treatment-emergent adverse events (TEAEs) between baricitinib and placebo across comorbidity subgroups (table 1). The most common TEAEs for the overall population were nasopharyngitis (5.6\%, baricitinib vs $5.2 \%$, placebo), upper respiratory tract infections $(4.5 \%$ vs $3.5 \%)$, urinary tract infections $(3.5 \%$ vs $2.6 \%)$ and bronchitis $(2.9 \%$ vs $2.6 \%)$. Serious adverse events (SAEs) and discontinuations were infrequent, occurring at similar rates across subgroups for baricitinib and placebo. SAE and discontinuation rates for baricitinib-treated patients with/without each comorbidity were generally close to overall rates, although numerical differences were observed between patients with depression (lower rates), osteoporosis (higher rates) or pulmonary disorders (higher rates) and those without these comorbidities.

In the LTE study, safety data were available from 3439 patients with a total of 6633 PYE to baricitinib. Overall, the incidence of TEAEs, SAEs, discontinuations and reported deaths was similar between patients with or without comorbidity within each comorbidity subgroup (table 1). Further, the exposure-adjusted incidence rates for all patients were lower in the LTE than during the placebo-controlled period for all safety outcomes assessed. The numerical differences between patients with/without each comorbidity observed after 16 weeks (see above) were not observed in the LTE study.

This is the first analysis assessing the impact of select comorbidities on the efficacy and safety of baricitinib $4 \mathrm{mg}$. Limitations of this post-hoc analysis include the analysis of patient data derived from randomised clinical trials rather than real-world patient data, such that patients with certain acute or historical conditions, unstable illness, or certain laboratory abnormalities were excluded from the trials (see online supplementary text); the limited number of patients in each comorbidity subgroup and the limited duration of analyses; the non-inclusion of all known comorbidities in RA; the mix of comorbidities included in each subgroup, which could vary in severity and overall impact on patients; the inability to assess adverse events of specific interest and whether comorbidity severity improved or worsened following baricitinib treatment; and the inability to conclude on the efficacy and safety of baricitinib in patients aged $\geq 75$ years and/or exposed to baricitinib $2 \mathrm{mg}$ due to low patient numbers. Planned analyses of safety data from registries or healthcare databases in the USA and Europe are expected to address many of the current limitations.

Baricitinib $4 \mathrm{mg}$ showed similar efficacy and safety during placebo-controlled and LTE observation periods regardless of the presence or absence of select comorbidities in patients with moderate-to-severe active RA and an inadequate response to csDMARDs. No trends for increased risk of safety events related to comorbidity were observed across comorbidity subgroups for baricitinib during a median exposure of 2 years. Further studies are needed to confirm the data presented, which provide a hypothesis only.

Trial registration numbers: NCT01185353, NCT01469013, NCT00902486, NCT01710358 and NCT01721057. 


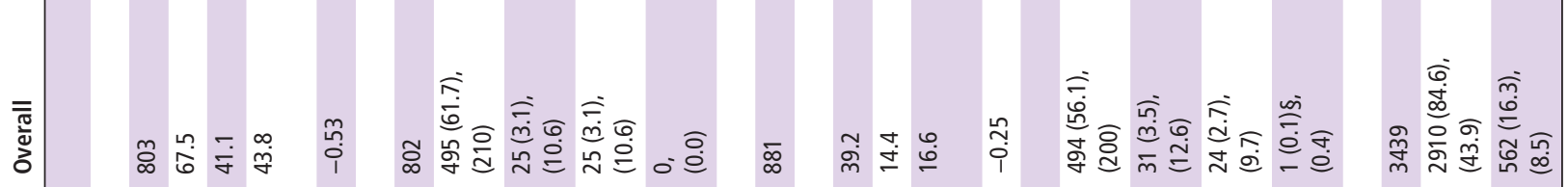

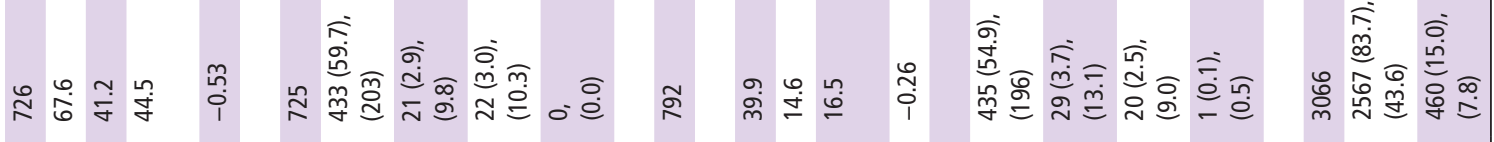

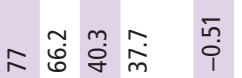

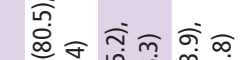

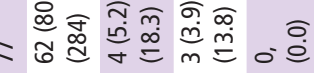

ळ

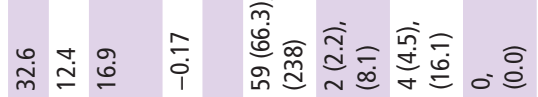

$\dot{\mathrm{o}} \overline{\mathrm{m}}$

ฮิธ

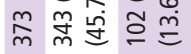

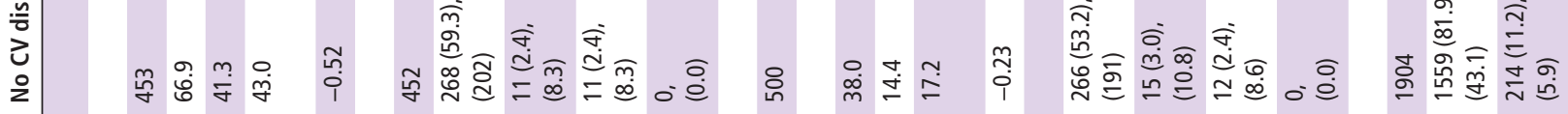

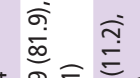

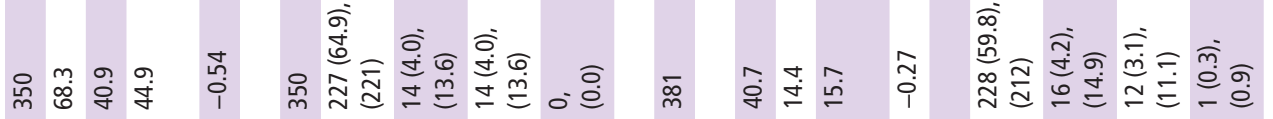

ธิ

$\stackrel{\infty}{\infty}$

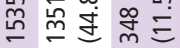

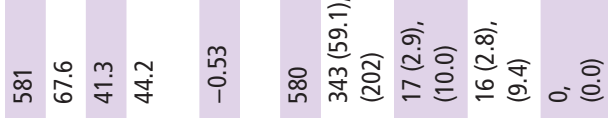

เั.

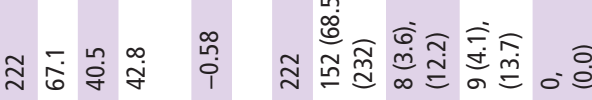

ז.

ดั ำ m $m$ น

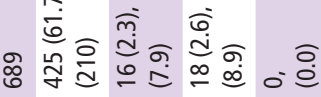

은

言

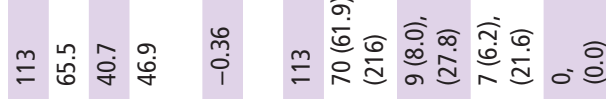

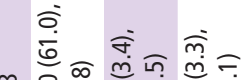

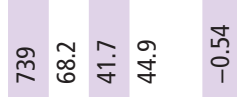

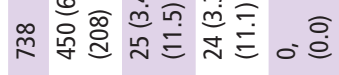

ธิ่

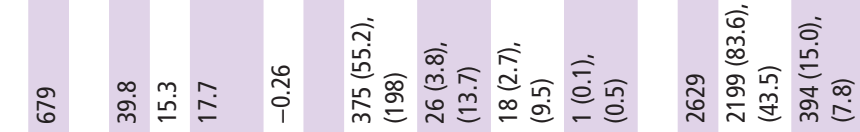

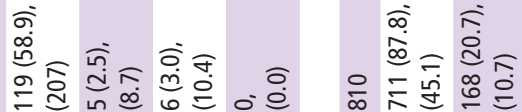

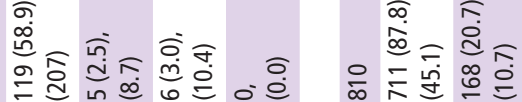
बิ $\stackrel{\infty}{\infty}$

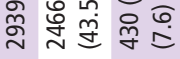
$\dot{\mathrm{o}} \overrightarrow{\mathrm{\sigma}}$ $\stackrel{\infty}{\infty}$ 这

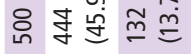

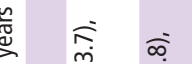

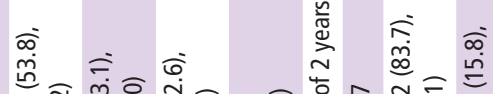

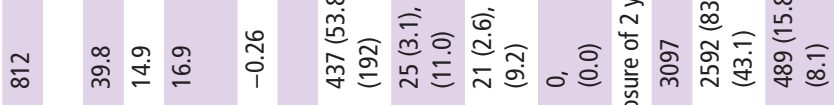

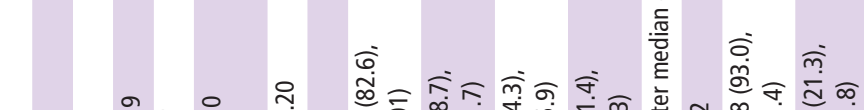

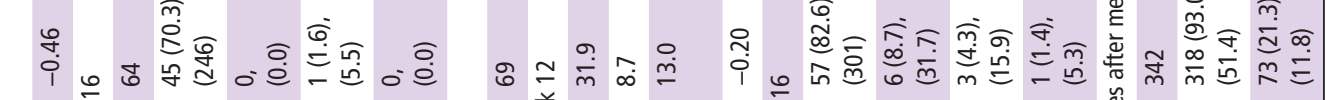

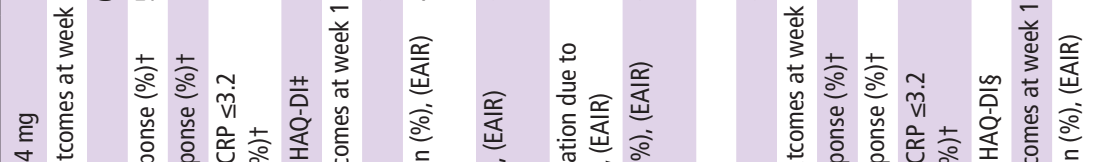

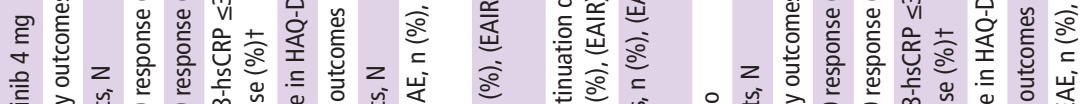

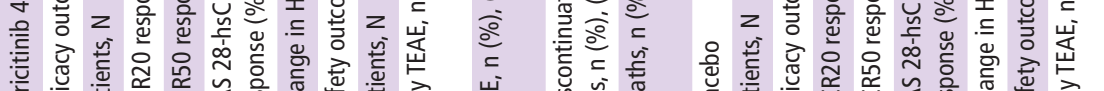

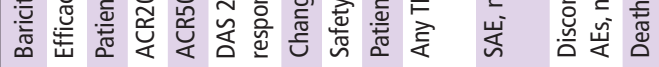

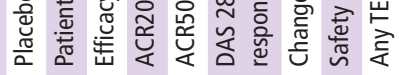

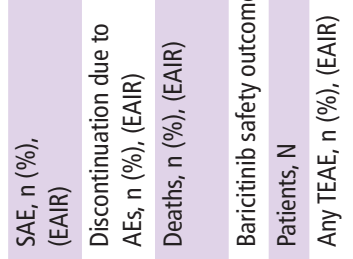

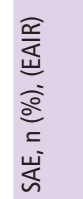




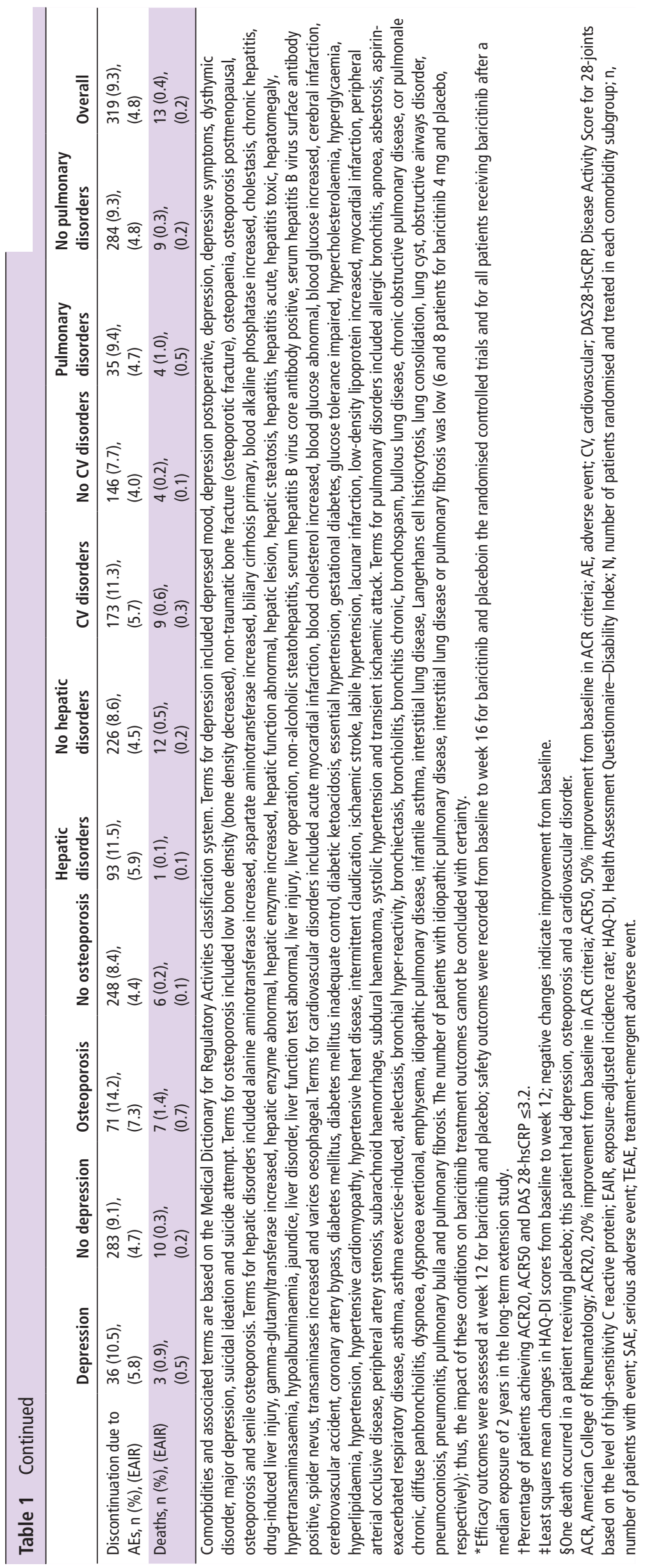


Bernard Combe, ${ }^{1}$ Alejandro Balsa, ${ }^{2}$ Piercarlo Sarzi-Puttini, ${ }^{3}$ Hans-Peter Tony, ${ }^{4}$ Inmaculada de la Torre, ${ }^{5}$ Veronica Rogai, ${ }^{5}$ Frederick Durand, ${ }^{5}$ Sarah Witt, ${ }^{5}$ Jinglin Zhong, ${ }^{6}$ Maxime Dougados ${ }^{7}$

${ }^{1}$ Rheumatology, CHU Montpellier, Montpellier University, Montpellier, France ${ }^{2}$ Hospital Universitario La Paz, Madrid, Spain

${ }^{3}$ L Sacco University Hospital, Milan, Italy

${ }^{4}$ University Hospital of Würzburg, Würzburg, Germany

${ }^{5}$ Eli Lilly and Company, Indianapolis, Indiana, USA

${ }^{6}$ IQVIA, North Carolina, USA

${ }^{7}$ René Descartes University, Hôpital Cochin, Paris, France

Correspondence to Professor Bernard Combe, Department of Rheumatology, CHU Montpellier and University of Montpellier, Hôpital Lapeyronie, 371 Avenue du Doyen Gaston Giraud, 34295 Montpellier cedex 5, France; b-combe@chumontpellier.fr

\section{Handling editor Josef S Smolen}

Acknowledgements The authors would like to acknowledge loannis Nikas, PhD, and Sue Chambers, PhD (Rx Communications, Mold, UK) for medical writing assistance during the preparation of this research letter, funded by Eli Lilly and Company.

Contributors All authors contributed substantially to the conception or design of the work, or the acquisition, analysis or interpretation of data for the work; drafted the work or revised it critically for important intellectual content; gave their final approval of the version to be published; and agreed to be accountable for all aspects of the work in ensuring that questions related to the accuracy or integrity of any part of the work are appropriately investigated and resolved.

Funding This study was funded by Eli Lilly and Company and Incyte Corporation. IdIT, VR, FD and SW are employees of Eli Lilly and Company and, together with the other authors, were involved in the study design; in the collection, analysis and interpretation of the data; in the writing of the report; and in the decision to submit the paper for publication.

Competing interests $B C$ reports grants and personal fees from Merck and Pfizer, and personal fees from AbbVie, BMS, Janssen, Eli Lilly, Roche Chugai, Sanofi and $U C B$, outside the submitted work. $A B$ reports grants and personal fees from Eli Lilly, during the conduct of the study, and grants from Pfizer, AbbVie, MSD and BMS, grants and personal fees from Novartis and Nordic, and personal fees from UCB, Celltrion, Kern Pharma, Sanofi and Sandoz, outside the submitted work. H-PT reports personal fees from AbbVie, Chugai, Janssen Cilag, Eli Lilly, Novartis, Roche, Sandoz Hexal and Sanofi Aventis, outside the submitted work. MD reports grants and personal fees from Eli Lilly, Pfizer, AbbVie and UCB, during the conduct of the study. VR is a minor shareholder of Eli Lilly and Company. PSP, JZ, IdIT, FD and SW report no conflicts of interest.

Patient consent Obtained.

Ethics approval All studies were conducted in accordance with the ethical principles of the Declaration of Helsinki and Good Clinical Practice guidelines. Studies were approved by the following review boards: NCT01469013: Parexel \#205204; NCT01185353: Schulman Associates IRB, IRB \#10-5255-0; NCT00902486: Copernicus Group IRB \#PAR1-09-143; NCT01710358 (RA-BEAM): Quorum Review IRB \#27257; NCT01721057 (RA-BUILD): Quorum Review IRB \#27258. In addition, studies were approved by each participating centre's institutional review board or ethics committee.

Provenance and peer review Not commissioned; externally peer reviewed.

Data sharing statement The data will not be shared as they are proprietary information.

\section{6 \\ OPEN ACCESS}

Open access This is an open access article distributed in accordance with the Creative Commons Attribution Non Commercial (CC BY-NC 4.0) license, which permits others to distribute, remix, adapt, build upon this work non-commercially, and license their derivative works on different terms, provided the original work is properly cited, appropriate credit is given, any changes made indicated, and the use is non-commercial. See: http://creativecommons.org/licenses/by-nc/4.0/.

(C) Author(s) (or their employer(s)) 2019. Re-use permitted under CC BY-NC. No commercial re-use. See rights and permissions. Published by BMJ.

- Additional material is published online only. To view please visit the journal online (http://dx.doi.org/10.1136/annrheumdis-2018-214261).

\section{Check for updates}

To cite Combe B, Balsa A, Sarzi-Puttini P, et al. Ann Rheum Dis 2019;78:1135-1138.

Received 10 August 2018

Revised 7 February 2019

Accepted 8 February 2019

Published Online First 6 March 2019

Ann Rheum Dis 2019;78:1135-1138. doi:10.1136/annrheumdis-2018-214261

\section{REFERENCES}

1 Dougados M, Soubrier M, Antunez A, et al. Prevalence of comorbidities in rheumatoid arthritis and evaluation of their monitoring: results of an international, cross-sectional study (COMORA). Ann Rheum Dis 2014;73:62-8.

2 Keystone EC, Taylor PC, Drescher E, et al. Safety and efficacy of baricitinib at 24 weeks in patients with rheumatoid arthritis who have had an inadequate response to methotrexate. Ann Rheum Dis 2015:74:333-40.

3 Tanaka Y, Emoto K, Cai Z, et al. Efficacy and safety of baricitinib in Japanese patients with active rheumatoid arthritis receiving background methotrexate therapy: a 12-week, double-blind, randomized placebo-controlled study. J Rheumatol 2016:43:504-11.

4 ClinicalTrials.gov. INCB028050 compared to background therapy in patients with active rheumatoid arthritis (RA) with inadequate response to disease modifying antirheumatic drugs, 2009. Available: https://clinicaltrials.gov/ct2/show/NCT00902486 [Accessed 18 Mar 2018].

5 Dougados $M$, van der Heijde D, Chen $Y$-C, et al. Baricitinib in patients with inadequate response or intolerance to conventional synthetic DMARDs: results from the RA-BUILD study. Ann Rheum Dis 2017;76:88-95.

6 Taylor PC, Keystone EC, van der Heijde D, et al. Baricitinib versus placebo or adalimumab in rheumatoid arthritis. N Engl J Med 2017:376:652-62. 